\title{
Specific carotenoid intake is inversely associated with the risk of breast cancer among Chinese women
}

\author{
Lian Wang ${ }^{1}$, Bin $\mathrm{Li}^{1}$, Mei-Xia Pan ${ }^{2}$, Xiong-Fei Mo ${ }^{3}$, Yu-Ming Chen ${ }^{1}$ and Cai-Xia Zhang ${ }^{1 *}$ \\ ${ }^{1}$ Department of Medical Statistics and Epidemiology, School of Public Health, Sun Yat-sen University, 74 Zhongshan Road 2, \\ Guangzhou 510080, People's Republic of China \\ ${ }^{2}$ Department of Clinical Nutrition, Guangdong General Hospital (Guangdong Academy of Medical Sciences), Guangzhou, \\ People's Republic of China \\ ${ }^{3}$ Department of Vascular Surgery, The First Affiliated Hospital of Sun Yat-sen University, Guangzhou, \\ People's Republic of China
}

(Submitted 17 June 2013 - Final revision received 18 November 2013 - Accepted 22 November 2013 - First published online 6 February 2014)

\begin{abstract}
The protective effect of dietary carotenoid intake on the risk of breast cancer is inconclusive. Moreover, data on dietary carotenoids in relation to breast cancer in non-Western populations are scarce. The aim of the present study was to examine the association between dietary carotenoid intake and the risk of breast cancer among Chinese women. A total of 561 cases and 561 controls who were frequency matched by age (5-year interval) and residence were recruited in the present case-control study. Dietary intake information was collected by a face-to-face interview using a validated FFQ. The OR and $95 \% \mathrm{CI}$ were assessed by multivariate logistic regression after adjusting for various potential confounders. An inverse association was observed between the consumption of $\alpha$-carotene, $\beta$-carotene, $\beta$-cryptoxanthin and lutein/zeaxanthin and the risk of breast cancer. The multivariate-adjusted OR for the highest quartile of intake compared with the lowest quartile of intake were 0.61 (95\% CI $0.43,0.88$ ) for $\alpha$-carotene, 0.54 (95\% CI $0.38,0.78$ ) for $\beta$-carotene, 0.38 (95\% CI 0.26 , 0.52 ) for $\beta$-cryptoxanthin and $0.49(95 \%$ CI $0.34,0.71)$ for lutein/zeaxanthin. Lycopene intake was not found to be associated with the risk of breast cancer, with the adjusted OR of 0.89 (95\% CI $0.61,1.30$ ). These inverse associations were more evident among pre-menopausal women and women who were exposed to second-hand smoke. The protective effect of specific carotenoid intake was observed for all subtypes of hormone receptor status of breast cancer. The present study indicated that a greater intake of specific carotenoids was associated with a decreased risk of breast cancer among Chinese women residing in Guangdong.
\end{abstract}

Key words: Carotenoids: Breast cancer: Case-control studies: China

Many previous epidemiological studies ${ }^{(1-3)}$ have shown a protective role of fruit and vegetables in breast cancer. The possible protective compounds in fruit and vegetables may include carotenoids. Carotenoids are lipid-soluble pigments present in red, yellow, orange and dark-green fruit and vegetables. The main carotenoids are $\alpha$-carotene, $\beta$-carotene, lycopene, $\beta$-cryptoxanthin, lutein and zeaxanthin ${ }^{(4)}$.

There are several mechanisms to be proposed in which specific carotenoids may act as a protective factor against breast cancer. Besides their overall influence on the enhancement of immune function, the protection of cells against DNA damage, the stimulation of gap junctional intercellular communication, the induction of detoxifying enzymes and the inhibition of cellular proliferation, it has been shown that they also have specific activities. $\alpha$-Carotene may suppress cytochrome $\mathrm{P} 450$ 1A1, an activator of procarcinogens ${ }^{(5)}$.
$\beta$-Carotene may control growth-inhibitory and pro-apoptotic effects in cancer cells through the redox regulation of the nuclear transcription factor $\mathrm{NF}-\kappa^{(6)}$. $\beta$-Cryptoxanthin may stimulate the expression of $R B$, an anti-oncogene, and $p 73$, a p53-related gene ${ }^{(7)}$; lycopene is the most efficient singlet oxygen quencher in vitro ${ }^{(8)}$, whereas lutein and zeaxanthin are scavengers of radical oxygen species ${ }^{(9)}$.

Fruit and vegetables differ in their nutrient content as groups. To account for huge differences in the nutrient content of the variety of fruit and vegetables, it is worthwhile to perform studies at the nutrient level, i.e. to test for the association between dietary carotenoid intakes (derived from food consumption data) and the risk of breast cancer. However, the findings from epidemiological studies on carotenoid intakes in relation to the risk of breast cancer have been inconclusive. Some case-control studies ${ }^{(10-20)}$ and cohort

Abbreviations: ER, oestrogen receptor; PR, progesterone receptor; SHS, second-hand smoke.

*Corresponding author: Associate Professor C.-X. Zhang, fax + 8620 87330446, email zhangcx3@mail.sysu.edu.cn; email chinazhangcaixia@hotmail.com 
studies $^{(21-26)}$ have noted an inverse association of breast cancer with specific carotenoid intakes, whereas others have not $^{(27-30)}$. A few studies ${ }^{(13,23,26)}$ have suggested that the protective effect of specific carotenoid intake on the risk of breast cancer was mainly confined to smokers. The association of $\beta$-carotene intake with the risk of breast cancer was stronger among women who consumed $15 \mathrm{~g}$ or more of alcohol per $\mathrm{d}^{(24)}$. Moreover, some studies ${ }^{(21,23)}$ have reported that the associations between carotenoid intakes and the risk of breast cancer are stratified by oestrogen receptor (ER) and progesterone receptor (PR) status. However, most of the aforementioned studies have been conducted in Western countries. More research in non-Western populations is needed to clarify this association.

Chinese populations generally have a high intake of carotenoid-rich vegetables and fruit ${ }^{(1)}$. The rates of active cigarette smoking and alcohol consumption among Chinese women are very low. However, the passive smoking rate of female was high $(43.6 \%)^{(31)}$. This provided a good opportunity to examine the relationship between carotenoid intake and the risk of breast cancer among non-smoking, non-alcohol drinking women. However, few studies have been conducted so far among Chinese women to examine this issue ${ }^{(12)}$. Therefore, the purpose of the present study was to investigate the relationship between dietary carotenoid ( $\alpha$-carotene, $\beta$-carotene, $\beta$-cryptoxanthin, lutein/zeaxanthin and lycopene) intake and the risk of breast cancer among Chinese women.

\section{Materials and methods}

\section{Study subjects}

This is an ongoing case-control study beginning in September 2011. The details of this study have been reported previously $^{(32)}$. In brief, potential case subjects were recruited from patients admitted to the three teaching and general hospitals in the areas being studied. Inclusion criteria were female subjects aged 25-70 years old and natives of Guangdong province or having lived in Guangdong for at least 5 years, with histologically confirmed breast cancer diagnosed within 3 months before the interview. Women were excluded if they had a prior history of breast cancer or other cancers. During September 2011 to May 2013, a total of 561 (93.3\%) cases out of 601 eligible cases took part in the study. Control subjects were patients with no history of any cancers and admitted to the same hospitals during the same time period as the case subjects. They were frequency matched by age (5-year interval) and residence (rural/urban) to the case patients. They were selected from the Departments of Ophthalmology, Plastic and Reconstructive Surgery, Vascular Surgery and Ear-Nose-Throat. Totally, 561 (94.4\%) controls out of 594 eligible controls were successfully interviewed.

The present study was conducted according to the guidelines laid down in the Declaration of Helsinki, and all procedures involving human subjects were approved by the Ethical Committee of School of Public Health, Sun Yat-sen University. Written informed consent was obtained from all subjects.

\section{Data collection}

Data were collected by trained interviewers through a face-toface interview based on a structured and previously validated questionnaire on sociodemographic data, current weight, height, menstrual and reproductive history, menopausal status, use of exogenous hormones, use of contraceptive drugs, family history of cancer, medical history, medication treatment, dietary habits, active and passive smoking, alcohol drinking and physical activities. BMI was calculated by dividing body weight (in $\mathrm{kg}$ ) by height (in $\mathrm{m}$ ) squared. Relevant medical diagnosis, histological findings, and ER and PR status were abstracted from the medical records. Regular smoking was defined as smoking at least one cigarette per $\mathrm{d}$ for more than six consecutive months. Exposure to secondhand smoke (SHS) was defined as non-smokers who reported being exposed to the smoke exhaled by smokers at least $15 \mathrm{~min} 1 \mathrm{~d}$ in a week. Regular drinking was defined as drinking alcohol at least once per week over the past year.

\section{Dietary intake assessment}

An interviewer-administered $\mathrm{FFQ}^{(33)}$ consisting of eighty-one food items was used to collect information on habitual dietary intake during the previous year before diagnosis for breast cancer patients or before the time of interview for controls. The daily nutrient intakes of energy, $\alpha$-carotene, $\beta$-carotene, lycopene, $\beta$-cryptoxanthin and lutein/zeaxanthin were calculated by summing the product of the frequency of consumption, the usual portion consumed and the nutrient content of each food item. The nutrient content values were derived from the Chinese Food Composition Table ${ }^{(34)}$ and the US Department of Agriculture nutrient database ${ }^{(35)}$. Food pictures with usual portion size were provided to help participants quantify the portions consumed.

The reproducibility and validity of the FFQ have been assessed previously ${ }^{(33)}$. The correlation coefficients between two FFQ administered 1 year apart were 0.41 for $\alpha$-carotene, 0.47 for $\beta$-carotene, 0.60 for $\beta$-cryptoxanthin, 0.51 for lycopene and 0.42 for lutein/zeaxanthin. The correlation coefficients for the FFQ and $18 \mathrm{~d}$ dietary records were 0.23 for $\alpha$-carotene, 0.37 for $\beta$-carotene, 0.35 for $\beta$-cryptoxanthin, $0 \cdot 30$ for lycopene and $0 \cdot 20$ for lutein/zeaxanthin.

\section{Statistical analysis}

All statistical analyses were conducted using SPSS 13.0 software, and the significance level set at 0.05 for the two-tailed $P$ value. Demographic characteristics and potential risk factors were compared between the cases and controls using the $t$ test or Wilcoxon rank-sum test for continuous variables and the $\chi^{2}$ test for categorical variables. Quartiles of specific carotenoids were defined based on the distribution of the controls. Unconditional logistic regression models were used to calculate OR and $95 \% \mathrm{CI}$ of each quartile using the lowest quartile group as the reference. The relationships between carotenoid intake and the risk of breast cancer were further examined after adjusting for various potential confounding factors 
using multivariate logistic regression models. Income, BMI (continuous), passive smoking (yes/no) and first-degree relative with cancer (yes/no) were selected as potential confounders based on the comparison of baseline characteristics between the cases and controls. Total energy intake was also adjusted using the residual method ${ }^{(36)}$. Tests for trend were performed by entering the categorical variables as continuous variables in the models.

Breast cancer defined by ER and PR status appears to be aetiologically and clinically heterogeneous ${ }^{(37,38)}$. The analysis stratified by ER and PR status was also performed to determine whether the association between carotenoid intake varied with ER and PR status. Because some risk factors for breast cancer have different associations among pre- and postmenopausal women ${ }^{(39)}$, the relationships between specific carotenoid intake and the risk of breast cancer may differ by menopausal status. Therefore, stratified analysis by menopausal status (pre- $v$. postmenopausal) was conducted. Stratified analysis by passive smoking status was also conducted. The interactions between menopausal status, passive smoking and carotenoid intake on the risk of breast cancer were evaluated using a multiplicative model. The product term was included in the multivariate logistic regression to test for multiplicative interaction. Furthermore, sensitivity analysis was conducted by excluding women with smoking history and alcohol consumption.

\section{Results}

The sociodemographic and other characteristics of the study subjects are shown in Table 1. Compared with the controls, the cases were more likely to have a history of first-degree relative with cancer and a history of passive smoking from other persons, and were more likely to have a lower household income. No significant differences were observed between the cases and controls in educational level, marital status, BMI, use of oral contraceptive, alcohol consumption or reproductive factors, including age at menarche, age at menopause, nulliparous, number of live births, age at first live birth and months of breast-feeding.

The mean intakes of main food groups and carotenoids are presented in Table 2. Compared with the controls, intakes of $\alpha$-carotene, $\beta$-carotene, $\beta$-cryptoxanthin, lycopene, lutein/ zeaxanthin, total energy, vegetables and white meat were significantly lower in the case subjects, whereas red meat intake was significantly higher in the case subjects.

The main food source of $\alpha$-carotene was carrots. $\beta$-carotene was mainly from spinach and carrots. $\beta$-Cryptoxanthin was supplied by oranges and papaya, whereas lycopene was from watermelon and tomatoes. Lutein and zeaxanthin were derived primarily from spinach and broccoli.

The OR and corresponding 95\% CI for breast cancer risk according to specific carotenoid intakes are summarised in Table 3. After adjustment for income, passive smoking, first-degree relative with cancer and total energy intake, a significant inverse association was observed between dietary intakes of $\alpha$-carotene, $\beta$-carotene, $\beta$-cryptoxanthin and lutein/ zeaxanthin and the risk of breast cancer. The multivariate OR for the highest quartile of intake compared with the lowest quartile of intake were 0.59 (95\% CI 0.42, 0.85) for $\alpha$-carotene, 0.52 (95\% CI $0.36,0.74)$ for $\beta$-carotene, 0.35 (95\% CI 0.25 , 0.52 ) for $\beta$-cryptoxanthin and 0.48 (95\% CI $0.33,0.69)$ for lutein/zeaxanthin. Further adjustment for other dietary factors including white meat and red meat intakes did not change the results appreciably. No significant association was found between lycopene intake and the risk of breast cancer, with the adjusted OR of 0.89 (95\% CI 0.61, 1.30).

Information on the ER and PR status of the tumour was available for $492(87.7 \%)$ of the cases. Of these breast cancer cases, the cases positive for ER and PR accounted for $383(77 \cdot 8 \%)$ and $357(72 \cdot 5 \%)$, respectively. Of the total 561 cases, 353 were ER-positive and PR-positive (ER+PR+), 105 were ER-negative and PR-negative (ER-PR-), thirty were ER-positive and $\mathrm{PR}$-negative $(\mathrm{ER}+\mathrm{PR}-)$, four were ER-negative and PR-positive $(\mathrm{ER}-\mathrm{PR}+)$ and sixty-nine were undefined. ER-PR+ breast cancers were not analysed separately because of the small number of cases. An inverse association between dietary intakes of $\alpha$-carotene, $\beta$-carotene, $\beta$-cryptoxanthin and lutein/zeaxanthin and the risk of breast cancer was observed in all subtypes as defined by ER and/or PR status, although there was no statistical significance among women with $\mathrm{ER}+/ \mathrm{PR}-$ breast cancer tumours (Table 4).

Table 5 shows the association between carotenoid intake and the risk of breast cancer stratified by menopausal status. An inverse association between dietary intakes of $\alpha$-carotene, $\beta$-carotene and lutein/zeaxanthin and the risk of breast cancer was only found in pre-menopausal but not in postmenopausal women. However, $\beta$-cryptoxanthin intake was observed to be inversely associated with the risk of breast cancer in both pre- and postmenopausal women. Lycopene intake was not related to the risk of breast cancer regardless of menopausal status.

Stratified analyses by passive smoking status were also conducted. Except for $\beta$-cryptoxanthin, an inverse association between dietary intakes of $\alpha$-carotene, $\beta$-carotene and lutein/ zeaxanthin and the risk of breast cancer was confined to non-smoking women who were exposed to SHS. No relationship was found between lycopene intake and the risk of breast cancer in all women or in specific type of women (Table 6).

In the present study, there were eighteen women who were current or former smokers, and restricting the analysis to non-smokers yielded results similar to those of the overall group. Sensitivity analysis excluding women with alcohol consumption was also conducted, and the results showed no substantial change (data not shown)

\section{Discussion}

The present hospital-based case-control study evaluated the relationship between carotenoid intake and the risk of breast cancer among Chinese women. The results showed that consumption of $\alpha$-carotene, $\beta$-carotene, $\beta$-cryptoxanthin and lutein/zeaxanthin was inversely associated with the risk of breast cancer. The protective effect of specific carotenoid intake on the risk of breast cancer may be more pronounced 
Table 1. Sociodemographic and selected risk factors of breast cancer among breast cancer cases and controls (Mean values and standard deviations; number of subjects and percentages)

\begin{tabular}{|c|c|c|c|c|c|}
\hline & \multicolumn{2}{|c|}{ Cases ( $n 561)$} & \multicolumn{2}{|c|}{ Controls ( $n$ 561) } & \multirow[b]{2}{*}{$P$} \\
\hline & $n$ & $\%$ & $n$ & $\%$ & \\
\hline Age (years) & & & & & 0.279 \\
\hline Mean & \multicolumn{2}{|c|}{$47 \cdot 56$} & \multicolumn{2}{|c|}{$48 \cdot 18$} & \\
\hline SD & \multirow{2}{*}{\multicolumn{2}{|c|}{9.53}} & \multicolumn{2}{|c|}{9.64} & \\
\hline Marital status & & & & & 0.732 \\
\hline Married & 531 & 92.9 & 518 & $92 \cdot 3$ & \\
\hline Unmarried/divorced/widowed & 40 & $7 \cdot 1$ & 43 & $7 \cdot 7$ & \\
\hline Educational level & & & & & 0.727 \\
\hline Primary school or below & 143 & 25.5 & 132 & 23.5 & \\
\hline Junior high school & 137 & 24.4 & 134 & 23.9 & \\
\hline Senior high school/secondary technical school & 148 & $26 \cdot 4$ & 164 & $29 \cdot 2$ & \\
\hline College or above & 133 & 23.7 & 131 & 23.4 & \\
\hline Occupation & & & & & 0.463 \\
\hline Administrator/other white collar worker & 176 & 31.4 & 193 & 34.4 & \\
\hline Blue collar worker & 207 & 36.9 & 206 & $36 \cdot 7$ & \\
\hline Farmer/other & 178 & 31.7 & 162 & 28.9 & \\
\hline Income (yuan/month) & & & & & $<0.001$ \\
\hline$<2000$ & 131 & 23.4 & 72 & $12 \cdot 8$ & \\
\hline $2001-5000$ & 170 & $30 \cdot 3$ & 162 & 28.9 & \\
\hline $5001-8000$ & 150 & $26 \cdot 7$ & 172 & 31.0 & \\
\hline$>8000$ & 110 & $19 \cdot 6$ & 153 & $27 \cdot 3$ & \\
\hline BMI $\left(\mathrm{kg} / \mathrm{m}^{2}\right)$ & & & & & 0.169 \\
\hline Mean & & & & & \\
\hline SD & & & & & \\
\hline Regular drinker & 47 & $8 \cdot 4$ & 32 & $5 \cdot 7$ & 0.080 \\
\hline Regular smoker & 8 & 1.4 & 10 & 1.8 & 0.635 \\
\hline Passive smoker & 356 & 64.4 & 266 & $48 \cdot 3$ & $<0.001$ \\
\hline Physical activity (exercise for health) & & & & & 0.281 \\
\hline Never & 221 & 39.4 & 247 & $44 \cdot 0$ & \\
\hline Occasionally & 30 & $5 \cdot 3$ & 26 & 4.6 & \\
\hline$\geq 1$ time/week & 310 & $55 \cdot 3$ & 288 & $51 \cdot 3$ & \\
\hline Age at menarche (years) & & & & & 0.590 \\
\hline Mean & & & & & \\
\hline SD & & & & & \\
\hline Nulliparous & 28 & $5 \cdot 0$ & 26 & $4 \cdot 7$ & 0.961 \\
\hline Number of live births* & & & & & 0.372 \\
\hline Mean & & & & & \\
\hline SD & & & & & \\
\hline Age at first live birth (years) ${ }^{*}$ & & & & & $0 \cdot 158$ \\
\hline Mean & & & & & \\
\hline SD & & & & & \\
\hline Months of breast-feeding $\dagger$ & & & & & 0.275 \\
\hline Mean & & & & & \\
\hline SD & & & & & \\
\hline Age at menopause (years) $\ddagger$ & & & & & 0.157 \\
\hline Mean & & & & & \\
\hline SD & & & & & \\
\hline Menopausal status & & & & & 0.296 \\
\hline Pre-menopausal & 356 & 63.5 & 339 & 60.4 & \\
\hline Postmenopausal & 205 & 36.5 & 222 & 39.6 & \\
\hline First-degree relative with cancer & 124 & $22 \cdot 1$ & 76 & 13.5 & $<0.001$ \\
\hline Ever used an oral contraceptive & 37 & 6.6 & 39 & $7 \cdot 0$ & 0.812 \\
\hline
\end{tabular}

* Among women who have had a live birth.

†Among women who had breast-fed.

$\ddagger$ Among menopausal women.

among pre-menopausal women and women who were exposed to SHS; however, this inverse association did not differ by ER and PR subtypes of breast cancer status. No association was found between dietary lycopene intake and the risk of breast cancer.

The relationship between specific carotenoid intake and the risk of breast cancer has been examined in many epidemiological studies ${ }^{(3,12,13,21-27,30,40-43)}$. However, the results have been mixed. A meta-analysis of twenty-four case-control studies and eleven cohort studies has reported that dietary $\alpha$-carotene and $\beta$-carotene intakes could significantly reduce the risk of breast cancer by $9 \%$ (pooled relative risk 0.91 , $95 \%$ CI $0.85,0.98$ ) and 6\% (pooled relative risk 0.94, $95 \% \mathrm{CI}$ $0 \cdot 88,1 \cdot 00)$, respectively. However, no significant association was found between dietary intakes of $\beta$-cryptoxanthin, lycopene and lutein/zeaxanthin and the risk of breast cancer ${ }^{(44)}$. 
Table 2. Consumption of specific carotenoids and selected dietary variables between breast cancer cases and controls (Mean values, and median values with their 25th-75th percentiles)

\begin{tabular}{|c|c|c|c|c|c|c|c|}
\hline & \multicolumn{3}{|c|}{ Cases ( $n 561)$} & \multicolumn{3}{|c|}{ Controls ( $n 561)$} & \multirow[b]{2}{*}{$P^{*}$} \\
\hline & Mean & Median & 25th-75th percentile & Mean & Median & 25th-75th percentile & \\
\hline Energy (kJ/d) & 6113 & 5945 & $4937-7050$ & 6297 & 6058 & $5100-7293$ & 0.001 \\
\hline$\alpha$-Carotene $(\mu \mathrm{g} / \mathrm{d})$ & 672 & 508 & $306-812$ & 747 & 542 & $326-946$ & $<0.001$ \\
\hline$\beta$-Carotene $(\mu \mathrm{g} / \mathrm{d})$ & 6004 & 5126 & $3732-7577$ & 6538 & 5594 & $3933-8382$ & $<0.001$ \\
\hline$\beta$-Cryptoxanthin $(\mu \mathrm{g} / \mathrm{d})$ & $87 \cdot 0$ & 67.5 & $42 \cdot 1-105$ & 115 & $82 \cdot 7$ & $49 \cdot 8-135$ & $<0.001$ \\
\hline Lycopene $(\mu \mathrm{g} / \mathrm{d})$ & 1070 & 713 & $334-1354$ & 1218 & 812 & $358-1410$ & 0.009 \\
\hline Lutein/zeaxanthin $(\mu \mathrm{g} / \mathrm{d})$ & 5720 & 4890 & $3279-6996$ & 6293 & 5388 & $3511-7999$ & $<0.001$ \\
\hline Vegetables (g/d) & 399 & 352 & $258-491$ & 424 & 374 & $273-529$ & $<0.001$ \\
\hline Fruits $(g / d)$ & 176 & 138 & $85 \cdot 9-233$ & 186 & 148 & $88 \cdot 4-244$ & 0.077 \\
\hline Red meat $(\mathrm{g} / \mathrm{d})$ & $98 \cdot 1$ & $85 \cdot 7$ & $57 \cdot 1-130$ & 94.8 & $83 \cdot 4$ & $54 \cdot 3-122$ & 0.033 \\
\hline White meat $(\mathrm{g} / \mathrm{d})$ & 102 & $80 \cdot 0$ & $47 \cdot 8-133$ & 109 & $85 \cdot 7$ & $54 \cdot 3-142$ & $<0.001$ \\
\hline
\end{tabular}

*Wilcoxon rank-sum test comparing the median consumption levels between the cases and controls.

Another meta-analysis including ten prospective studies has also indicated an inverse association between the risk of breast cancer and dietary $\beta$-carotene intake, with a pooled relative risk of $0.95(95 \% \mathrm{CI} 0.91,0.99)^{(45)}$. The only research conducted in China has shown an inverse association of higher dietary intakes of $\beta$-carotene, $\beta$-cryptoxanthin and lycopene with a reduced risk of breast cancer ${ }^{(12)}$. The present findings are consistent with these studies. However, some studies have not shown the beneficial effects of specific carotenoid intake on the risk of breast cancer ${ }^{(27,28,30,43)}$.
Epidemiological studies examining the associations between carotenoid intakes and the risk of breast cancer by ER and PR status are limited, and the results are inconsistent. A pooled analysis of eighteen prospective cohort studies has suggested that dietary intakes of $\alpha$-carotene, $\beta$-carotene and lutein/zeaxanthin were associated with a modestly lower risk of ER-, but not ER+, breast cancer ${ }^{(46)}$. However, the Women's Health Initiative Observational Study of 84805 postmenopausal women has found that dietary intakes of $\alpha$ carotene, $\beta$-carotene and lycopene were inversely associated

Table 3. Risk for breast cancer according to quartiles of the daily intake of carotenoids

(Odds ratios and $95 \%$ confidence intervals)

\begin{tabular}{|c|c|c|c|c|c|}
\hline & No. of cases/controls & Crude OR & $95 \% \mathrm{Cl}$ & Adjusted OR* & $95 \% \mathrm{Cl}$ \\
\hline \multicolumn{6}{|l|}{$\alpha$-Carotene } \\
\hline$<326.37$ & $164 / 140$ & 1.00 & & 1.00 & \\
\hline $326 \cdot 37-542 \cdot 27$ & $157 / 140$ & 0.97 & $0.69,1.36$ & 0.81 & $0.58,1.15$ \\
\hline $542 \cdot 27-945 \cdot 61$ & $142 / 141$ & 0.83 & $0.59,1.18$ & 0.81 & $0.58,1.15$ \\
\hline$>945.61$ & $98 / 140$ & 0.65 & $0.45,0.93$ & 0.61 & $0.43,0.88$ \\
\hline$P$ for trend & & 0.014 & & 0.013 & \\
\hline \multicolumn{6}{|l|}{$\beta$-Carotene } \\
\hline$<3933.00$ & $80 / 140$ & 1.00 & & 1.00 & \\
\hline $3933.00-5593.64$ & $152 / 140$ & 0.84 & $0.61,1.16$ & 0.81 & $0.57,1.13$ \\
\hline $5593.64-8382.49$ & $141 / 139$ & 0.79 & $0.57,1.09$ & 0.74 & $0.53,1.05$ \\
\hline$>8382.49$ & $88 / 142$ & 0.48 & $0.34,0.68$ & 0.54 & $0.38,0.78$ \\
\hline$P$ for trend & & $<0.001$ & & 0.001 & \\
\hline \multicolumn{6}{|l|}{$\beta$-Cryptoxanthin } \\
\hline$<49.76$ & $195 / 140$ & 1.00 & & 1.00 & \\
\hline $49 \cdot 76-82 \cdot 67$ & $204 / 140$ & 1.05 & $0.77,1.42$ & 0.90 & $0.64,1.27$ \\
\hline $82 \cdot 67-135 \cdot 17$ & $91 / 141$ & 0.46 & $0.33,0.65$ & 0.41 & $0.28,0.60$ \\
\hline$>135 \cdot 17$ & $71 / 140$ & 0.36 & $0.18,0.41$ & 0.38 & $0.26,0.52$ \\
\hline$P$ for trend & & $<0.001$ & & $<0.001$ & \\
\hline \multicolumn{6}{|l|}{ Lycopene } \\
\hline$<358.50$ & $135 / 140$ & 1.00 & & 1.00 & \\
\hline $358.50-811.60$ & $143 / 141$ & 1.05 & $0.76,1.47$ & 0.91 & $0.62,1.32$ \\
\hline $811.60-1410.03$ & $157 / 140$ & $1 \cdot 16$ & $0.84,1.62$ & 0.99 & $0.68,1.46$ \\
\hline$>1410.03$ & $126 / 140$ & 0.93 & $0.67,1.31$ & 0.89 & $0.61,1.30$ \\
\hline$P$ for trend & & 0.871 & & 0.687 & \\
\hline \multicolumn{6}{|l|}{ Lutein/zeaxanthin } \\
\hline$<3510.94$ & $182 / 140$ & 1.00 & & 1.00 & \\
\hline $3510 \cdot 94-5387 \cdot 79$ & $175 / 141$ & 0.96 & $0.70,1.31$ & 0.91 & $0.65,1.26$ \\
\hline $5387 \cdot 79-7999 \cdot 28$ & $120 / 140$ & 0.66 & $0.48,0.92$ & 0.64 & $0.45,0.94$ \\
\hline$>7999.28$ & $84 / 140$ & 0.46 & $0.33,0.65$ & 0.49 & $0.34,0.71$ \\
\hline$P$ for trend & & $<0.001$ & & $<0.001$ & \\
\hline
\end{tabular}

${ }^{*}$ Adjusted for income, second-hand smoke, first-degree relative with cancer, total energy intake, red meat intake and white meat intake. 
Table 4. Risk for breast cancer according to quartiles of the daily intake of carotenoids stratified by oestrogen receptor (ER) and/or progesterone receptor (PR) status (Odds ratios and $95 \%$ confidence intervals)

\begin{tabular}{|c|c|c|c|c|c|c|c|c|c|c|c|c|c|c|c|c|c|c|c|c|c|}
\hline & \multicolumn{3}{|c|}{ ER+ } & \multicolumn{3}{|c|}{ ER- } & \multicolumn{3}{|c|}{$\mathrm{PR}+$} & \multicolumn{3}{|c|}{$\mathrm{PR}-$} & \multicolumn{3}{|c|}{$\mathrm{ER}+\mathrm{PR}+$} & \multicolumn{3}{|c|}{$\mathrm{ER}+\mathrm{PR}-$} & \multicolumn{3}{|c|}{ ER-PR- } \\
\hline & $\begin{array}{l}\text { No. of } \\
\text { cases/ } \\
\text { controls }\end{array}$ & $\begin{array}{c}\text { Adjusted } \\
\mathrm{OR}^{*} \\
\end{array}$ & $95 \% \mathrm{Cl} \mathrm{C}$ & $\begin{array}{c}\text { No. of } \\
\text { cases/ } \\
\text { controls }\end{array}$ & $\begin{array}{c}\text { Adjusted } \\
\mathrm{OR}^{\star} \\
\end{array}$ & $95 \% \mathrm{Cl}$ & $\begin{array}{c}\text { No. of } \\
\text { cases/ } \\
\text { controls }\end{array}$ & $\begin{array}{c}\text { Adjusted } \\
\mathrm{OR}^{\star} \\
\end{array}$ & $95 \% \mathrm{Cl}$ & $\begin{array}{l}\text { No. of } \\
\text { cases/ } \\
\text { controls }\end{array}$ & $\begin{array}{c}\text { Adjusted } \\
\mathrm{OR}^{\star} \\
\end{array}$ & $95 \% \mathrm{Cl}$ & $\begin{array}{c}\begin{array}{c}\text { No. of } \\
\text { cases/ } \\
\text { controls }\end{array} \\
\end{array}$ & $\begin{array}{c}\text { Adjusted } \\
\mathrm{OR}^{\star}\end{array}$ & $95 \% \mathrm{Cl}$ & $\begin{array}{l}\text { No. of } \\
\text { cases/ } \\
\text { controls }\end{array}$ & $\begin{array}{c}\text { Adjusted } \\
\mathrm{OR}^{\star} \\
\end{array}$ & $95 \% \mathrm{Cl}$ & $\begin{array}{c}\begin{array}{l}\text { No. of } \\
\text { cases/ } \\
\text { controls }\end{array} \\
\end{array}$ & $\begin{array}{c}\text { Adjusted } \\
\mathrm{OR}^{\star}\end{array}$ & $95 \% \mathrm{Cl}$ \\
\hline \multicolumn{22}{|l|}{$\alpha$-Carotene } \\
\hline$<326 \cdot 37$ & D/140 & 1.00 & & $35 / 140$ & 1.00 & & $100 / 140$ & 1.00 & & $45 / 140$ & 1.00 & & $99 / 140$ & 1.00 & & $11 / 140$ & 1.00 & & $4 / 140$ & 1.00 & \\
\hline 32 & $108 / 140$ & 0.84 & $7,1.23$ & $31 / 140$ & 0.74 & $0.41,1.33$ & $102 / 140$ & 0.85 & $0.57,1.25$ & $37 / 140$ & 0.73 & $0.43,1 \cdot 24$ & $102 / 140$ & 0.86 & $58,1 \cdot 27$ & $6 / 140$ & 0.54 & $0.19,1.54$ & $31 / 140$ & 0.77 & $0.43,1.39$ \\
\hline $542 \cdot 27-945 \cdot 61$ & $94 / 141$ & 0.79 & $0.54,1.17$ & $27 / 141$ & 0.74 & $0.41,1.34$ & $87 / 141$ & 0.78 & $0.52,1 \cdot 15$ & $34 / 141$ & 0.77 & $0.45,1 \cdot 31$ & $86 / 141$ & 0.78 & $0.52,1 \cdot 16$ & $8 / 141$ & 0.74 & $0.28,1.94$ & $26 / 141$ & 0.74 & $0.40,1.36$ \\
\hline$>945.6$ & $71 / 140$ & 0.65 & $0.44,0.97$ & $16 / 140$ & 0.51 & $0.26,1.00$ & $68 / 140$ & 0.67 & $0.44,1.01$ & $19 / 140$ & 0.47 & $0.26,0.87$ & $66 / 140$ & 0.66 & $0.44,1.00$ & $5 / 140$ & 0.47 & $0.16,1.41$ & $14 / 140$ & 0.47 & $0.23,0.94$ \\
\hline$P$ for trend & & 0.035 & & & 0.062 & & & 0.05 & & & 0.026 & & & 0.042 & & & 0.246 & & & 0.040 & \\
\hline \multicolumn{22}{|l|}{$\beta$-Carotene } \\
\hline$<3933.00$ & $116 / 140$ & 1.00 & & $46 / 140$ & 1.00 & & $109 / 140$ & 1.00 & & $53 / 140$ & 1.00 & & $108 / 140$ & 1.00 & & $8 / 140$ & 1.00 & & $45 / 140$ & 1.00 & \\
\hline 3933.00-5593.64 & $102 / 140$ & 0.81 & $0.55,1.18$ & $32 / 140$ & 0.71 & $0.41,1.22$ & $93 / 140$ & 0.76 & $0.51,1 \cdot 12$ & $41 / 140$ & 0.81 & $0.49,1 \cdot 33$ & $93 / 140$ & 0.77 & $0.52,1 \cdot 13$ & 9/140 & $1 \cdot 14$ & $0.42,3 \cdot 13$ & $32 / 140$ & 0.73 & $0.42,1.26$ \\
\hline 5593.64-8382.49 & $103 / 139$ & 0.83 & $0.57,1.20$ & $16 / 139$ & 0.35 & $0.19,0.68$ & $95 / 139$ & 0.80 & $0.54,1.17$ & $24 / 139$ & 0.47 & $0.27,0.82$ & $93 / 139$ & 0.79 & $0.53,1 \cdot 16$ & $10 / 139$ & 1.22 & $0.46,3.25$ & $93 / 139$ & 0.31 & $0.16,0.62$ \\
\hline$>8382.49$ & $62 / 142$ & 0.57 & $0.38,0.85$ & $15 / 142$ & 0.37 & $0.19,0.71$ & $60 / 142$ & 0.57 & $0.38,0.87$ & $17 / 142$ & 0.36 & $0.20,0.68$ & $59 / 142$ & 0.57 & $0.38,0.87$ & $3 / 142$ & 0.39 & $0.10,1.51$ & $14 / 142$ & 0.35 & $0.18,0.69$ \\
\hline$P$ for trend & & 0.012 & & & $<0.001$ & & & 0.015 & & & $<0.001$ & & & 0.014 & & & 0.282 & & & $<0.001$ & \\
\hline \multicolumn{22}{|l|}{$\beta$-Cryptox } \\
\hline $\begin{array}{l}<49.7 \\
49.76-\end{array}$ & 8/140 & 1.00 & & $35 / 140$ & 1.00 & & $122 / 140$ & 1.00 & & $51 / 140$ & 1.00 & & $121 / 140$ & 1.00 & & $17 / 140$ & 1.00 & & $34 / 140$ & 1.00 & \\
\hline $49.76-82$. & $135 / 140$ & 0.80 & $0.55,1 \cdot 17$ & $46 / 140$ & 1.17 & $0.66,2$ & $132 / 140$ & 0.91 & $0.62,1 \cdot 33$ & $49 / 140$ & 0.82 & $0.49,1 \cdot 36$ & $130 / 140$ & 0.90 & $0.61,1.32$ & $15 / 140$ & 0.23 & $0.08,0.68$ & $44 / 140$ & 1.16 & $0.65,2.05$ \\
\hline $82 \cdot 67-1$ & $58 / 141$ & 0.35 & $0.23,0.55$ & $18 / 141$ & 0.50 & $0.25,1.00$ & $57 / 141$ & 0. & $0.25,0.61$ & $19 / 141$ & 0.35 & 0.18 & $56 / 141$ & 0.39 & $0.25,0.61$ & $2 / 1$ & 0.10 & $0.02,0.45$ & $17 / 141$ & 0 & J.24, 1.01 \\
\hline $\begin{array}{l}>135.17 \\
\text { Pfortrend }\end{array}$ & $52 / 140$ & $\begin{array}{r}0.38 \\
-0.00\end{array}$ & $0.25,0.59$ & $10 / 140$ & 0.34 & $0.15,0.75$ & $46 / 140$ & $\begin{array}{r}0.39 \\
-0.00\end{array}$ & $0.25,0.61$ & $16 / 140$ & 0.34 & $0.18,0.66$ & $46 / 140$ & 0.4 & $0.25,0.62$ & $6 / 140$ & 0.29 & $0.10,0.82$ & $10 / 140$ & 0.35 & $0.16,0.79$ \\
\hline \multicolumn{22}{|l|}{ Lycopene } \\
\hline$<358.50$ & $92 / 140$ & 1.00 & & $29 / 140$ & 1.00 & & $82 / 140$ & 1.00 & & $39 / 140$ & 1.00 & & $82 / 140$ & 1.00 & & $10 / 140$ & 1.00 & & $29 / 140$ & 1.00 & \\
\hline 358.50 & 97 & 0.87 & $0.57,1.32$ & $27 / 1$ & 0.90 & $0.46,1.74$ & $91 / 141$ & 0. & $0.59,1.39$ & 331 & 0.81 & $0.44,1.46$ & $89 / 141$ & 0. & $0.57,1.36$ & $8 / 1$ & 0.76 & $0.26,2.22$ & 25/141 & $0 . \varepsilon$ & $0.42,1.61$ \\
\hline $811 \cdot 60-141$ & $112 / 140$ & 0.9 & $0.64,1.51$ & $26 / 140$ & 0.82 & $0.41,1.64$ & $109 / 140$ & 1.0 & $0.69,1.67$ & $29 / 140$ & 0.66 & $0.35,1.24$ & $108 / 140$ & 1.0 & $0.69,1.66$ & $4 / 140$ & 0.36 & $0.10,1.32$ & $25 / 140$ & 0.3 & $0.39,1.57$ \\
\hline$>1410.03$ & $82 / 140$ & 0.84 & $0.55,1 \cdot 29$ & $27 / 140$ & 1.03 & $0.53,2.00$ & $75 / 140$ & 0.85 & $0.54,1.32$ & $34 / 140$ & 0.96 & $0.53,1.74$ & $74 / 140$ & 0.84 & $0.54,1.31$ & $8 / 140$ & 0.87 & $0.29,2.58$ & $26 / 140$ & 1.01 & $0.51,1.97$ \\
\hline \multirow{3}{*}{\multicolumn{22}{|c|}{ Lutein/zeaxanthin }} \\
\hline & & & & & & & & & & & & & & & & & & & & & \\
\hline & & & & & & & & & & & & & & & & & & & & & \\
\hline $3510 \cdot 94-5387.79$ & $111 / 141$ & 0.87 & $0.60,1 \cdot 25$ & $38 / 141$ & 0.88 & $0.52,1.49$ & $105 / 141$ & 0.88 & $0.61,1 \cdot 28$ & $44 / 141$ & 0.85 & $0.52,1.39$ & $104 / 141$ & 0. & $0.61,1.28$ & $7 / 141$ & 0.74 & $0.26,2.06$ & $37 / 141$ & 0.88 & $0.52,1.50$ \\
\hline 5387.7 & $87 / 140$ & 0.67 & $0.46,0.99$ & $17 / 140$ & 0.43 & $0.22,0.81$ & $79 / 140$ & 0.65 & $0.44,0.96$ & $25 / 140$ & 0.52 & $0.30,0.91$ & $78 / 140$ & 0.65 & $0.44,0.96$ & 9/140 & 0.98 & $0.37,2.61$ & $16 / 140$ & 0.41 & $0.21,0.79$ \\
\hline $\begin{array}{l}>7999.28 \\
\text { P for trend }\end{array}$ & $63 / 140$ & $\begin{array}{l}0.54 \\
0.001\end{array}$ & $0.36,0.81$ & $12 / 140$ & $\begin{array}{c}0.31 \\
<0.001\end{array}$ & $0.15,0.64$ & $59 / 140$ & $\begin{array}{l}0.54 \\
0.001\end{array}$ & $0.36,0.82$ & $16 / 140$ & $\begin{array}{r}0.35 \\
<0.001\end{array}$ & $0.19,0.66$ & $58 / 140$ & $\begin{array}{l}0.54 \\
0.001\end{array}$ & $0.36,0.82$ & $5 / 140$ & $\begin{array}{l}0.56 \\
0.451\end{array}$ & $0.18,1.74$ & $11 / 140$ & $\begin{array}{c}0.30 \\
<0.001\end{array}$ & $0.14,0.62$ \\
\hline
\end{tabular}

${ }^{*}$ Adjusted for income, passive smoking, first-degree relative with cancer, total energy intake, red meat intake and white meat intake. 
with the risk of ER+PR+ breast cancer, but not with other breast cancer groups jointly defined by ER and PR status $^{(21)}$. In the Long Island Breast Cancer Study, $\beta$-carotene intake was found to be inversely associated with ER+PR+ and $\mathrm{ER}-\mathrm{PR}-$ tumours in postmenopausal women ${ }^{(3)}$. The results of the present study suggested that dietary intakes of $\alpha$-carotene, $\beta$-carotene, $\beta$-cryptoxanthin and lutein/ zeaxanthin were inversely associated with all breast cancer subtypes as defined by ER and PR status.

In the present study, the protective effect of specific carotenoid intakes including $\alpha$-carotene, $\beta$-carotene, $\beta$-cryptoxanthin and lutein/zeaxanthin on the risk of breast cancer was mainly observed in pre-menopausal women. In consistent with the present study, some previous studies assessing the association by menopausal status have provided some evidence of an inverse association for pre-menopausal women ${ }^{(13,19,20,24,26)}$, although relatively few studies have observed this relationship in postmenopausal women ${ }^{(3,22)}$. The Collaborative Breast Cancer Study has found that a higher intake of $\beta$-carotene (OR 0.81, $95 \%$ CI $0 \cdot 68,0 \cdot 98$ ) and lutein/zeaxanthin (OR 0.83, $95 \%$ CI 0.68, 0.99) from food was associated with a statistically significant lower risk among pre-menopausal women ${ }^{(13,24)}$. Other two earlier studies ${ }^{(19,20)}$ have also found the beneficial effects of high dietary $\beta$-carotene intake on the reduced risk of pre-menopausal breast cancer. The possible mechanism of this inverse association observed among pre-menopausal women is unclear and needs to be verified by more studies. Although the protective effect of $\alpha$-carotene, $\beta$-carotene and lutein/zeaxanthin intakes on the risk of breast cancer was not found among postmenopausal women, due to the lower numbers involved in the stratified analysis, chance or low statistical power was more likely to explain some of these non-significant associations. Therefore, studies with larger sample size are needed to clarify this association.

Only ten cases and eight controls were active smokers in the present study. However, $57 \cdot 2$ and $42 \cdot 8 \%$ of breast cancer cases and controls were second-hand smokers. Multivariate analyses stratified by passive smoking status showed that the observed inverse association between dietary intakes of $\alpha$-carotene, $\beta$-carotene, $\beta$-cryptoxanthin and lutein/zeaxanthin and the risk of breast cancer was only confined to women exposed to SHS. So far, no previous studies have elevated the effect modification of passive smoking status on the relationship between carotenoid intake and the risk of breast cancer. However, three previous studies examined the modifying effects of active smoking status on carotenoid intake and the risk of breast cancer. The Nurses' Health Study $\mathrm{II}^{(26)}$ has shown that dietary intakes of $\alpha$-carotene and $\beta$-carotene were associated with a reduced risk of breast cancer among current smokers. The Collaborative Breast Cancer Study ${ }^{(13)}$, a large population-based case-control study, has found a significant inverse association between dietary intakes of $\alpha$-carotene, $\beta$-carotene and lutein/zeaxanthin and the risk of breast cancer among ever smokers. The Swedish Cohort study ${ }^{(23)}$ has also shown that dietary intakes of $\alpha$-carotene and $\beta$-carotene were inversely associated with the risk of breast cancer among ever smokers. These findings are consistent with a protective influence of a carotenoid-rich diet on reactive oxygen species-induced damage from tobacco smoke. It is well 
known that smoking causes oxidative stress and that smokers have lower plasma levels of some carotenoids. It has been suggested that during both passive and active smoking, oxidative stress is clearly exacerbated ${ }^{(47)}$. This might be the possible reason of the protective effect of specific carotenoid intake on the risk of breast cancer among passive smokers observed in the present study. Further studies conducted in different ethnic populations will be needed to clarify this issue.

The present study had some limitations. First, selection bias is a potential limitation in hospital-based case-control studies. The hospital-based controls may not be representative of the general population and dietary habits may be different from the general population. Another concern is that the controls recruited from hospitals may have conditions potentially related to diet. To minimise this bias, we recruited controls from several conditions with no apparent associations with a dietary cause. In addition, the high participation rate (93.3 and $94.4 \%$ for cases and controls, respectively) and high comparability in sociodemographic factors between the two groups indicated that selection bias should not be a serious problem. Second, recall bias can be a threat to retrospective study design. The controls did not have a malignancy problem and their recall of past dietary exposures might differ from the cases. The presence of breast cancer among the case subjects might act as a stimulus, affecting the patient's perception of a possible exposure to a hypothesised risk factor ${ }^{(48)}$. For example, breast cancer cases may have adopted a healthier eating behaviour after diagnosis which may have influenced their self-report of dietary intake. On the other hand, dietary intake of breast cancer cases may have been adversely affected by the presence of the disease. To minimise this bias, we tried to interview cases as soon as diagnosis was made. In addition, in the present study, greater effort was made to interview cases before their surgery. Moreover, food photographs with usual intake portions were provided to assist participants with quantification of intake. To improve the comparability of the recall between the cases and controls, all interviews were conducted in a hospital setting and a standardised questionnaire interview method was used among both cases and controls. Third, random measurement error in the estimation of usual intake is also of concern. Dietary intake assessed by FFQ is less precise than some other methods and may involve some measurement error. However, the results of the validation study showed that the FFQ had satisfactory reproducibility and reasonable validity. Therefore, the probability of bias arising from measurement error should be reduced in the present results.

In conclusion, dietary intakes of $\alpha$-carotene, $\beta$-carotene, $\beta$-cryptoxanthin and lutein/zeaxanthin were inversely associated with the risk of breast cancer among Chinese women. This protective effect may be more pronounced among premenopausal and SHS status women.

\section{Acknowledgements}

The authors very gratefully acknowledge the assistance of the student helper Juan Nie and the participation of the study subjects, without whom the study would not have been possible. 
The present study was jointly supported by the New Teachers' Fund for Doctor Stations, Ministry of Education of China (no. 20100171120057), the National Natural Science Foundation of China (no. 81102188) and the Open-Lab Fund of Sun Yat-sen University in 2011 (no. KF201140). The funders had no role in the design, analysis or writing of this article.

The authors' responsibilities were as follows: L. W. conducted the data collection, analysed the data and writing of the paper; B. L. participated in the data collection; M.-X. P. and X.-F. M. were responsible for connecting and coordinating the fieldwork; Y.-M. C. provided significant advice regarding the analyses and interpretation of the data; C.-X. Z. constructed the project design, supervised and contributed to the writing of the manuscript.

The authors have no conflicts of interest to declare.

\section{References}

1. Zhang CX, Ho SC, Chen YM, et al. (2009) Greater vegetable and fruit intake is associated with a lower risk of breast cancer among Chinese women. Int J Cancer 125, 181-188.

2. Shannon J, Ray R, Wu C, et al. (2005) Food and botanical groupings and risk of breast cancer: a case-control study in Shanghai, China. Cancer Epidemiol Biomarkers Prev 14, $81-90$.

3. Gaudet MM, Britton JA, Kabat GC, et al. (2004) Fruits, vegetables, and micronutrients in relation to breast cancer modified by menopause and hormone receptor status. Cancer Epidemiol Biomarkers Prev 13, 1485-1494.

4. Mangels AR, Holden JM, Beecher GR, et al. (1993) Carotenoid content of fruits and vegetables: an evaluation of analytic data. J Am Diet Assoc 93, 284-296.

5. Cooper DA, Eldridge AL \& Peters JC (1999) Dietary carotenoids and certain cancers, heart disease, and age-related macular degeneration: a review of recent research. Nutr Rev 57, 201-214.

6. Hirsch K, Atzmon A, Danilenko M, et al. (2007) Lycopene and other carotenoids inhibit estrogenic activity of 17 betaestradiol and genistein in cancer cells. Breast Cancer Res Treat 104, 221-230.

7. Nishino H, Tokuda H, Murakoshi M, et al. (2000) Cancer prevention by natural carotenoids. Biofactors 13, 89-94.

8. Tsen KT, Tsen SW \& Kiang JG (2006) Lycopene is more potent than beta carotene in the neutralization of singlet oxygen: role of energy transfer probed by ultrafast Raman spectroscopy. J Biomed Opt 11, 064025.

9. Bohm F, Tinkler JH \& Truscott TG (1995) Carotenoids protect against cell membrane damage by the nitrogen dioxide radical. Nat Med 1, 98-99.

10. Levi F, Pasche C, Lucchini F, et al. (2001) Dietary intake of selected micronutrients and breast-cancer risk. Int J Cancer 91, 260-263.

11. Do MH, Lee SS, Jung PJ, et al. (2003) Intake of dietary fat and vitamin in relation to breast cancer risk in Korean women: a case-control study. J Korean Med Sci 18, 534-540.

12. Huang JP, Zhang M, Holman CD, et al. (2007) Dietary carotenoids and risk of breast cancer in Chinese women. Asia Pac J Clin Nutr 16, Suppl. 1, 437-442.

13. Mignone LI, Giovannucci E, Newcomb PA, et al. (2009) Dietary carotenoids and the risk of invasive breast cancer. Int J Cancer 124, 2929-2937.

14. Lee HP, Gourley L, Duffy SW, et al. (1991) Dietary effects on breast-cancer risk in Singapore. Lancet 337, 1197-1200.
15. Zaridze D, Lifanova Y, Maximovitch D, et al. (1991) Diet, alcohol consumption and reproductive factors in a casecontrol study of breast cancer in Moscow. Int J Cancer $\mathbf{4 8}$, 493-501.

16. Levi F, La Vecchia C, Gulie C, et al. (1993) Dietary factors and breast cancer risk in Vaud, Switzerland. Nutr Cancer 19, $327-335$.

17. Negri E, La Vecchia C, Franceschi S, et al. (1996) Intake of selected micronutrients and the risk of breast cancer. Int $J$ Cancer 65, 140-144.

18. Ronco A, De Stefani E, Boffetta P, et al. (1999) Vegetables, fruits, and related nutrients and risk of breast cancer: a case-control study in Uruguay. Nutr Cancer 35, 111-119.

19. Freudenheim JL, Marshall JR, Vena JE, et al. (1996) Premenopausal breast cancer risk and intake of vegetables, fruits, and related nutrients. J Natl Cancer Inst 88, 340-348.

20. Bohlke K, Spiegelman D, Trichopoulou A, et al. (1999) Vitamins $\mathrm{A}, \mathrm{C}$ and $\mathrm{E}$ and the risk of breast cancer: results from a case-control study in Greece. Br J Cancer 79, 23-29.

21. Cui Y, Shikany JM, Liu S, et al. (2008) Selected antioxidants and risk of hormone receptor-defined invasive breast cancers among postmenopausal women in the Women's Health Initiative Observational Study. Am J Clin Nutr 87, $1009-1018$

22. Nagel G, Linseisen J, van Gils CH, et al. (2010) Dietary betacarotene, vitamin $\mathrm{C}$ and $\mathrm{E}$ intake and breast cancer risk in the European Prospective Investigation into Cancer and Nutrition (EPIC). Breast Cancer Res Treat 119, 753-765.

23. Larsson SC, Bergkvist L \& Wolk A (2010) Dietary carotenoids and risk of hormone receptor-defined breast cancer in a prospective cohort of Swedish women. Eur J Cancer 46, 1079-1085.

24. Zhang S, Hunter DJ, Forman MR, et al. (1999) Dietary carotenoids and vitamins $\mathrm{A}, \mathrm{C}$, and $\mathrm{E}$ and risk of breast cancer. J Natl Cancer Inst 91, 547-556.

25. Jumaan AO, Holmberg L, Zack M, et al. (1999) Beta-carotene intake and risk of postmenopausal breast cancer. Epidemiology 10, 49-53.

26. Cho E, Spiegelman D, Hunter DJ, et al. (2003) Premenopausal intakes of vitamins A, C, and E, folate, and carotenoids, and risk of breast cancer. Cancer Epidemiol Biomarkers Prev 12, 713-720.

27. Terry P, Jain M, Miller AB, et al. (2002) Dietary carotenoids and risk of breast cancer. Am J Clin Nutr 76, 883-888.

28. Nkondjock A \& Ghadirian P (2004) Intake of specific carotenoids and essential fatty acids and breast cancer risk in Montreal, Canada. Am J Clin Nutr 79, 857-864.

29. Sesso HD, Buring JE, Zhang SM, et al. (2005) Dietary and plasma lycopene and the risk of breast cancer. Cancer Epidemiol Biomarkers Prev 14, 1074-1081.

30. Wang C, Baumgartner RN, Yang D, et al. (2009) No evidence of association between breast cancer risk and dietary carotenoids, retinols, vitamin C and tocopherols in Southwestern Hispanic and non-Hispanic White women. Breast Cancer Res Treat 114, 137-145.

31. Tao Xu EA (2010) Survey of smoking and passive smoking status among Chinese adults in 11 provinces. Chin J Prev Contr Chron Dis 18, 229-230.

32. Zhang CX, Pan MX, Li B, et al. (2013) Choline and betaine intake is inversely associated with breast cancer risk: a two-stage case-control study in China. Cancer Sci 104, $250-258$.

33. Zhang CX \& Ho SC (2009) Validity and reproducibility of a food frequency questionnaire among Chinese women in Guangdong province. Asia Pac J Clin Nutr 18, 240-250. 
34. Yang Y (2004) China Food Composition. Beijing: Peking University Medical Press.

35. Exler JKJ (2012) USDA national nutrient database for standard reference, release 25. http://www.ars.usda.gov/ Services/docs.htm?docid $=8964$

36. Willett WC, Howe GR \& Kushi LH (1997) Adjustment for total energy intake in epidemiologic studies. Am J Clin Nutr $\mathbf{6 5}$, 1220S-1228S, 1229S-1231S.

37. Althuis MD, Fergenbaum JH, Garcia-Closas M, et al. (2004) Etiology of hormone receptor-defined breast cancer: a systematic review of the literature. Cancer Epidemiol Biomarkers Prev 13, 1558-1568.

38. Ursin G, Bernstein L, Lord SJ, et al. (2005) Reproductive factors and subtypes of breast cancer defined by hormone receptor and histology. Br J Cancer 93, 364-371.

39. Huang Z, Hankinson SE, Colditz GA, et al. (1997) Dual effects of weight and weight gain on breast cancer risk. JAMA 278, 1407-1411.

40. Shibata A, Paganini-Hill A, Ross RK, et al. (1992) Intake of vegetables, fruits, beta-carotene, vitamin $\mathrm{C}$ and vitamin supplements and cancer incidence among the elderly: a prospective study. Br J Cancer 66, 673-679.

41. Christen WG, Liu S, Glynn RJ, et al. (2008) Dietary carotenoids, vitamins $\mathrm{C}$ and $\mathrm{E}$, and risk of cataract in women: a prospective study. Arch Ophthalmol 126, 102-109.
42. Sharhar S, Normah H, Fatimah A, et al. (2008) Antioxidant intake and status, and oxidative stress in relation to breast cancer risk: a case-control study. Asian Pac J Cancer Prev 9, 343-349.

43. Pan SY, Zhou J, Gibbons L, et al. (2011) Antioxidants and breast cancer risk - a population-based case-control study in Canada. BMC Cancer 11, 372.

44. Hu F, Wang YB, Zhang W, et al. (2012) Carotenoids and breast cancer risk: a meta-analysis and meta-regression. Breast Cancer Res Treat 131, 239-253.

45. Aune D, Chan DS, Vieira AR, et al. (2012) Dietary compared with blood concentrations of carotenoids and breast cancer risk: a systematic review and meta-analysis of prospective studies. Am J Clin Nutr 96, 356-373.

46. Zhang X, Spiegelman D, Baglietto L, et al. (2012) Carotenoid intakes and risk of breast cancer defined by estrogen receptor and progesterone receptor status: a pooled analysis of 18 prospective cohort studies. Am J Clin Nutr 95, 713-725.

47. Yokus B, Mete N, Cakir UD, et al. (2005) Effects of active and passive smoking on antioxidant enzymes and antioxidant micronutrients. Biotechnol Biotechnol Equip 19, 117-123.

48. Zhang CX, Ho SC, Lin FY, et al. (2011) Dietary fat intake and risk of breast cancer: a case-control study in China. Eur J Cancer Prev 20, 199-206. 